\title{
OS COMBUSTIBLES E AS MANUFACTURAS EN MADEIRA DURANTE A IDADE DO FERRO: ESTUDO ANTRACOLÓXICO DO XACEMENTO DE CASTROLANDÍN (CUNTIS, PONTEVEDRA)
}

\author{
MARÍA MARTíN SEIJO *
}

Resumo

O estudo antracolóxico do xacemento de Castrolandín (Cuntis, Pontevedra) ofrece información sobre o
consumo de especies leñosas como combustibles e para a elaboración de manufacturas nun xacemento
castrexo de interior cunha cronoloxía que vai do s. II ANE ata finais do s.I da nosa era.

Palavras - chave: Idade do Ferro, antracoloxía, combustibles, manufacturas en madeira.

\begin{abstract}
Woodfuel and the woodworking during the Iron Age: charcoal analysis data from Castrolandín (Cuntis, Pontevedra) - The charcoal analysis of the settlement of Castrolandin (Cuntis, Pontevedra) offers information about the tree species management for fuelwood and for woodworking in an Iron Age hillfort from s. II BC to s. I AC.
\end{abstract}

Key - words: Iron Age, charcoal analysis, woodfuel, woodworking.

\section{INTRODUCIÓN}

A análise dos carbóns arqueolóxicos permite obter información sobre determinadas actividades esenciais da vida cotiá das sociedades da Idade do Ferro, especialmente aquelas vinculadas á producción de enerxía térmica e lumínica. Os datos referidos ó uso e consumo de combustibles para alimentar os fogares domésticos e artesanais son os máis habituais, pero no caso da existencia de incendios permiten identificar outro tipo de usos da madeira: construcción, carpintería, etc. Os datos obtidos a partir do estudo antracolóxico do xacemento de Castrolandín permiten realizar unha aproximación ós tipos de materias primas leñosas utilizadas para estos fins nun asentamento castrexo dunha zona de interior ocupado dende o s. II ANE ó s. I da nosa era (Fig. 1). Durante a Idade do Ferro e especialmente cara o cambio de era os datos obtidos a partir de diversas análises paleobotánicas e edafolóxicas sinalan un cambio significativo na xestión do bosque, no que os sinais de deforestación pasan de ser locais a rexionais (MARTínEZCORTIZAS et al., 2005), e son introducidas prácticas de silvicultura que favorecen a expansión de determinadas especies forestais como Castanea e Juglans.

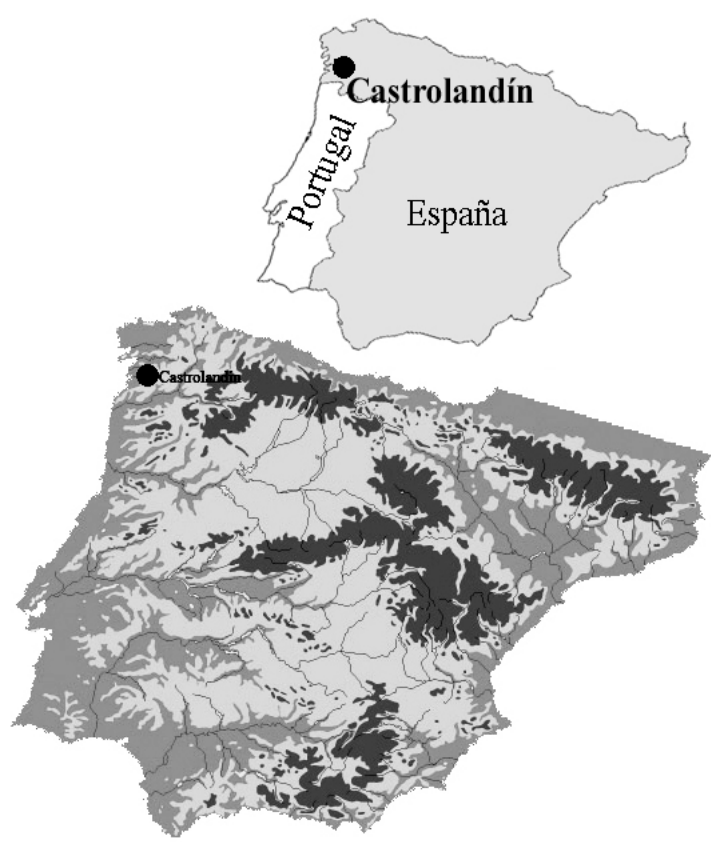

Fig. 1 - Localización do xacemento de Castrolandín (Cuntis, Pontevedra).

Fig. 1 - Location of the settlement of Castrolandín (Cuntis, Pontevedra).

* Grupo de Estudos para a Prehistoria do Noroeste Ibérico, Dep. Historia I-Universidade de Santiago de Compostela. 


\section{Contexto Bioxeográfico}

O xacemento localízase na rexión bioxeográfica atlántica ou eurosiberiana da Península Ibérica dentro do piso bioclimático colino ou basal (COSTA et al., 2001, RigUEIRO, 2003), no que a carballeira acidófila con xilbardeira (Rusco aculeatiQuercetosum roboris) constitúe a vexetación potencial desta zona. Durante o Subatlántico a vexetación característica segundo a información paleoambiental obtida a partir das análises polínicas son os bosques caducifolios, predominando claramente no estrato arbóreo o xénero Quercus, seguido de taxóns eurosiberianos como Betula, Alnus e Corylus (CARrión, 2003). O estrato arbustivo acada unha importante representación durante este periodo tanto nas secuencias polínicas como antracolóxicas documentándose a presenza de Fabaceae e Ericaceae.

A vexetación que rodea actualmente o xacemento está moi alterada pola repoboación con especies como o eucalipto e o piñeiro, sen embargo nalgunhas zonas próximas aínda podemos ver a vexetación autóctona integrada por formacións de caducifolios co carballo pedunculado (Quercus robur) como especie dominante, nos claros exemplares de espiño albar (Crataegus monogyna), e nas zonas máis húmidas formacións riparias (Alnus glutinos, Corylus avellana, Salix sp, Frangula alnus). As formacións arbustivas son as que teñen unha maior importancia con especies colonizadoras como Genista e Ulex, e nas zonas degradadas polos eucaliptos xeófitos como os fieitos.

\section{Contexto ArQueolóxico}

O xacemento de Castrolandín é un pequeno poboado fortificado, situado en Cuntis (Pontevedra), emprazado nun pequeno esporón que queda delimitado por dous cursos de auga. Ten unha croa de forma oval delimitada por un parapeto en todo o seu perimentro excepto na zona Oriental onde aproveita a pendente natural do terreo.

No que respecta ás estructuras documentadas na croa observouse a coexistencia de estructuras pétreas con outras realizadas en materiais perecedoiros, así como áreas de actividade ó aire libre. En zonas puntuais do asentamento documentáronse incendios que destruíron varias construccións que non foron ocupadas posteriormente polo que os materiais arqueolóxicos foron recuperados in situ.

A cronoloxía do asentamento a partir da tipoloxía dos materiais arqueolóxicos recuperados vai dende os inicios do s. II ANE ata finais do do s. I da nosa era.

As mostras analizadas proceden das intervencións levadas a termo polo Laboratorio de paleoambiente, patrimonio e paisaxe (LPPP) da USC e xestionadas pola Fundación Terra Termarum.

Durante o 2004 realizouse unha campaña de sondaxes e unha escavación en área no ano 2005. Os carbóns analizados foron recuperados de distintas áreas do asentamento (interior de construccións realizadas en pedra ou en materiais perecedoiros, espacios exteriores próximos ás construccións, zonas de actividade ó aire libre), e de diferentes contextos (niveis de recheo e nivelación, niveis de uso, niveis de incendio, e niveis de abandono).

\section{Material e Métodos}

Durante as intervencións arqueolóxicas recolléronse a man os fragmentos de carbón de maiores dimensións, e durante a campaña do 2005 paralelamente á escavación levouse a termo a flotación dos sedimentos que ofrecían unha maior concentración de restos arqueobotánicos.

Debido á importante cantidade de carbón recuperado despois do tamizado e da tria xa no laboratorio realizouse unha mostraxe, a partir dun volume constante de carbóns por cada bolsa resultante da flotación ou a totalidade da mostra no caso de non chegar á cantidade mínima.

A recollida combinada das mostras permitíu determinar unha sobrerrepresentación de determinadas especies arbóreas de madeira dura (Quercus sp caducifolio) fronte a outras especies de madeira máis branda ou de arbustos que proporcionan unha leña de menor calibre. Ademais na mostra resultante da flotación foi posible identificar unha maior variedade de taxóns arbóreos e arbustivos (Fig. 2).

O carbón foi observado nun microscopio de luz a reflexión con obxectivos 20x, 40x, 200x e 400x do Departamento de Historia I da Universidade de Santiago de Compostela.

Para a determinación realizáronse diferentes cortes no carbón buscando os tres planos anatómicos da madeira: transversal, lonxitudinal tanxencial e lonxitudinal radial. Unha vez observadas as características anatómicas comparouse cos atlas de anatomía de madeira de F.H. Schweingruber $(1978,1990)$, J.G. Hather (2000) e co de carbóns actuais e arqueolóxicos de J.-L.Vernet et al. (2001), e cunha colección de referencia de carbóns actuais. 


\begin{tabular}{|c|c|c|c|c|c|c|c|c|c|c|c|c|c|}
\hline \multirow{2}{*}{ 壱 } & $\diamond^{0}$ & $\stackrel{n}{2}$ & 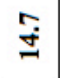 & $\overrightarrow{+}$ & กี & $I$ & $\dddot{8}$ & 3 & $\stackrel{\bullet}{+}$ & $\stackrel{\circ}{-}$ & $\stackrel{8}{8}$ & $\stackrel{-1}{-}$ & ఠ \\
\hline & Z & $\stackrel{\infty}{\circ}$ & $\infty$ & 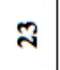 & - & 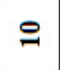 & - & $N$ & జ & $a$ & m & $a$ & 䐬 \\
\hline \multirow{2}{*}{$\begin{array}{l}* \\
\dot{b} \\
0 \\
0\end{array}$} & $0^{0}$ & 음 & & & & & & & & & & & ఏ్రీ \\
\hline & Z & $\infty$ & & & & & & & & & & & $\infty$ \\
\hline \multirow{2}{*}{ 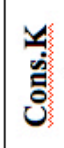 } & $\circ^{\circ}$ & 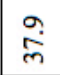 & $\vec{m}$ & $\stackrel{\sim}{m}$ & & & & & $\stackrel{m}{9}$ & & & $\stackrel{\beth}{\Xi}$ & 음 \\
\hline & Z & $=$ & $a$ & - & & & & & m & & & in & సి \\
\hline \multirow{2}{*}{$\begin{array}{l}7 \\
\text { aे } \\
\text { d. }\end{array}$} & $0^{0}$ & $\overrightarrow{\mathrm{f}}$ & $\hat{i}$ & $\stackrel{\infty}{\stackrel{\oplus}{\Theta}}$ & & & & & 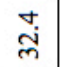 & & & & $\stackrel{8}{\circ}$ \\
\hline & $\ddot{z}$ & సి & - & 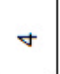 & & & & & $\simeq$ & & & & m \\
\hline \multirow{2}{*}{ 官 } & $\circ^{\circ}$ & $\stackrel{m}{i}$ & $\vec{\sim}$ & & & & & & & & & & $\Xi$ \\
\hline & Z & $m$ & $n$ & & & & & & & & & & $\stackrel{\infty}{\sim}$ \\
\hline \multirow{2}{*}{ 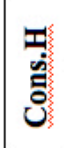 } & $\circ$ & సี & $\begin{array}{l}0 \\
\stackrel{\sim}{\Delta}\end{array}$ & $\vec{\Xi}$ & $\overrightarrow{\mathrm{i}}$ & & & & & & & & ఏ \\
\hline & Z & ก) & $m$ & $\infty$ & - & & & & & & & & F \\
\hline \multirow{2}{*}{$\begin{array}{l}5 \\
0 \\
03\end{array}$} & $0^{\circ}$ & $\approx$ & \pm & $\stackrel{+}{i}$ & & & & $\stackrel{\circ}{-}$ & $\stackrel{\circ}{-}$ & $\stackrel{d}{b}$ & 离 & $\begin{array}{l}\infty \\
0 \\
0\end{array}$ & $\stackrel{\Xi}{\mathrm{O}}$ \\
\hline & Z & ప & $=$ & m & & & & $N$ & $N$ & $\infty$ & $m$ & - & $\approx$ \\
\hline \multirow{2}{*}{ 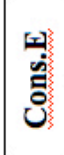 } & $\partial^{\circ}$ & $\frac{n}{\infty}$ & $\stackrel{9}{\dot{\Xi}}$ & & & $\overrightarrow{0}$ & & & $\because$ & $\hat{0}$ & & $\ddot{\circ}$ & ఏ \\
\hline & Z & $\stackrel{9}{\exists}$ & ㄱ. & & & - & & & $N$ & - & & - & $\stackrel{\mathscr{m}}{\sim}$ \\
\hline \multirow{2}{*}{ 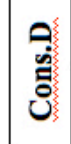 } & $\partial^{\circ}$ & $\stackrel{\vec{z}}{a}$ & $n$ & $\stackrel{\infty}{\stackrel{\infty}{N}}$ & & & & & & & & & ક્ \\
\hline & z & $m$ & $N$ & -7 & & & & & & & & & m \\
\hline \multirow{2}{*}{ 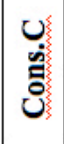 } & $\partial^{\circ}$ & $\infty$ & ㄱ. & & & & & & & & & & $\cong$ \\
\hline & Z & $\theta$ & - & & & & & & & & & & $"$ \\
\hline \multirow{2}{*}{ 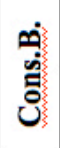 } & $0^{\circ}$ & $\hat{b}$ & $\stackrel{n}{త}$ & in & & $\stackrel{n}{r}$ & ò & & $\begin{array}{l}\infty \\
\dot{n}\end{array}$ & & & $\stackrel{0}{-}$ & $=$ \\
\hline & Z & $\infty$ & $\because$ & 0 & & $a$ & - & & $r$ & & & $N$ & ฐ \\
\hline \multicolumn{2}{|c|}{ 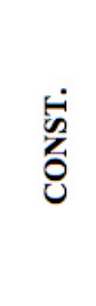 } & 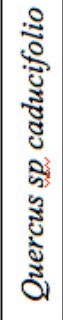 & $\begin{array}{l}\mathbb{Z} \\
\mathbb{Z} \\
\mathbb{Z} \\
\mathbb{Z}\end{array}$ & 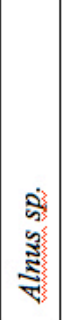 & 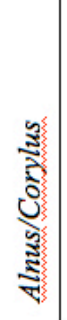 & $\begin{array}{l}\mathbb{8} \\
\mathbb{8} \\
\mathbb{8} \\
\mathbb{8} 3\end{array}$ & 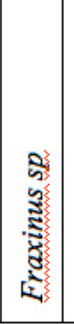 & 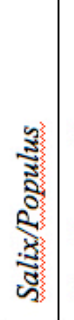 & 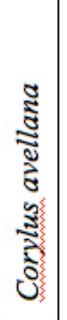 & 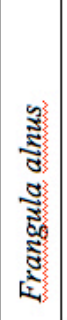 & 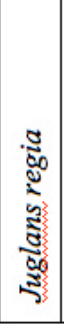 & 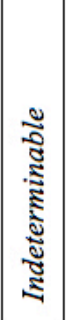 & 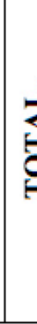 \\
\hline
\end{tabular}




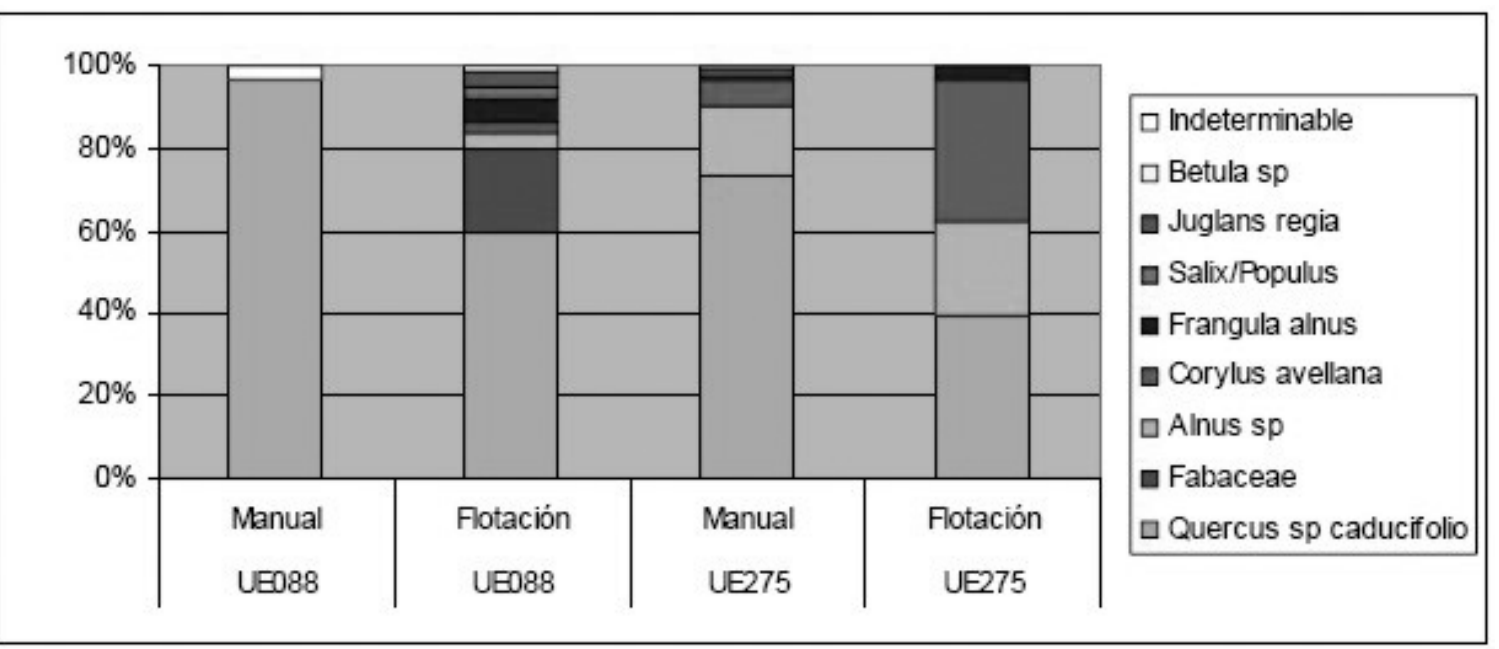

Fig. 2 - Riqueza taxonómica e porcentaxe de representación dos diferentes taxóns en función do tipo de mostraxe realizado.

Fig. 2 - Taxonomic variety and percentage of representation of different taxa depending on the sample process.

\section{Datos Antracolóxicos}

\subsection{Identificación taxonómica e comentarios}

A partir da análise estudáronse un total de 1166 fragmentos de carbón determinándose en total 12 taxóns: carballo (Quercus sp caducifolio), fabáceas tipo xesta-toxo (Fabaceae), ameneiro (Alnus sp), ameneiro-avelaira (Alnus/Corylus), maloideas tipo espiño albar (Maloideae), bidueiro (Betula sp), freixo (Fraxinus sp), salgueiro-chopo (Salix/Populus), abelaira (Corylus avellana), acivro (Ilex aquifolium), sanguiño (Frangula alnus), hedra (Hedera helix) e nogueira (Juglans regia).

Recuperáronse fragmentos de carbón dos depósitos interiores das construccións en pedra (B a J) e de dous fondos de cabana construídos con materiais perecedoiros (cons. K, cons.*, Táboa 1).
A especie máis representada neste tipo de estructuras é o carballo, seguido das fabáceas, e especies de ribeira como a abelaira e o ameneiro, as demais especies teñen unha presenza moi puntual.

Analizáronse 5 mostras de carbóns relacionadas con estructuras de combustión, identificándose unicamente 6 taxóns a partir 47 fragmentos de carbón recollidos manualmente. Entre os taxóns determinados predomina claramente o Quercus sp caducifolio $(80.9 \%)$, fronte ás demais especies determinadas Fabaceae (6.4\%), Corylus avellana (4.3\%) e máis puntualmente Alnus sp, Maloideae, e Fraxinus sp (2.1\%) (Táboa 2). A pouca diversidade taxonómica destas estructuras é habitual debido ós procesos de limpeza e mantemento ás que son sometidos estos dispositivos de combustión co fin de garantizar un correcto funcionamento, polo que só aparecen os restos dos derradeiros momentos de ocupación (PIQUÉ \& Ros, 2002)

Táboa 2 - Número absoluto $\left(\mathrm{N}^{\circ}\right)$ e porcentaxe (\%) dos taxóns nas estructuras de combustión.

Table 2 - Absolute number $\left(\mathrm{N}^{\circ}\right)$ and percentage (\%) of the taxa in the structures of fireplaces.

\begin{tabular}{|c|c|c|c|c|c|c|c|c|c|c|c|c|}
\hline \multirow{2}{*}{$\begin{array}{l}\text { ESTRUCTURAS DE } \\
\text { COMBUSTIÓN }\end{array}$} & \multicolumn{2}{|c|}{ UE048 } & \multicolumn{2}{|c|}{ UE065 } & \multicolumn{2}{|c|}{ UE148 } & \multicolumn{2}{|c|}{ UE176 } & \multicolumn{2}{|c|}{ UE294 } & \multicolumn{2}{|c|}{ TOTAL } \\
\hline & $\mathbf{N}^{\circ}$ & $\%$ & $\mathbf{N}^{\circ}$ & $\%$ & $\mathbf{N}^{\circ}$ & $\%$ & $\mathbf{N}^{0}$ & $\%$ & $\mathbf{N}^{0}$ & $\%$ & $\mathbf{N}^{\circ}$ & $\%$ \\
\hline Quercus sp caducifolio & 15 & 100 & & & 2 & 40 & 3 & 75 & 16 & 80 & 38 & 80.9 \\
\hline Fabaceae & & & & & & & & & 3 & 15 & 3 & 6.4 \\
\hline Alnus sp. & & & & & 1 & 20 & & & & & 1 & 2.1 \\
\hline Maloideae & & & & & & & & & 1 & 5 & 1 & 2.1 \\
\hline Fraxinus $s p$ & & & & & 1 & 20 & & & & & 1 & 2.1 \\
\hline Salix/Populus. & & & & & & & & & & & 0 & 0 \\
\hline Corylus avellana & & & & & 1 & 20 & 1 & 25 & & & 2 & 4.3 \\
\hline Indeterminable & & & 1 & 100 & & & & & & & 1 & 2.1 \\
\hline TOTAL & 15 & 100 & 3 & 100 & 5 & 100 & 4 & 100 & 20 & 100 & 47 & 100 \\
\hline
\end{tabular}


Os resultados obtidos dos carbóns recollidos en áreas de actividade ó aire libre, espazos entre construccións e en zonas vinculadas ó parapeto de terra que rodea $o$ asentamento ofrecen unha importante variedade de taxóns, sendo nas zonas entre construccións onde se localizaron os fragmentos de madeira carbonizados con sinais de traballo de carpintería (Táboa 3).

Táboa 2 - Taxóns identificados en zonas exteriores ás construccións, patios e en relación ó parapeto.

Table 3 - Taxa identified in areas outside the buildings, related with courtyards and with the parapet.

\begin{tabular}{|c|c|c|c|c|c|c|c|c|}
\hline \multirow[t]{2}{*}{$\begin{array}{c}\text { ZONAS } \\
\text { EXTERIORES }\end{array}$} & \multicolumn{2}{|c|}{$\begin{array}{l}\text { Entre } \\
\text { cons. } \\
\text { D-F }\end{array}$} & \multicolumn{2}{|c|}{$\begin{array}{l}\text { Entre } \\
\text { cons. } \\
\text { B-C }\end{array}$} & \multicolumn{2}{|c|}{$\begin{array}{l}\text { Exte- } \\
\text { riores }\end{array}$} & \multicolumn{2}{|c|}{$\begin{array}{l}\text { Para- } \\
\text { peto }\end{array}$} \\
\hline & $\mathbf{N}^{0}$ & $\%$ & $\mathbf{N}^{0}$ & $\%$ & $\mathbf{N}^{0}$ & $\%$ & $\mathbf{N}^{0}$ & $\%$ \\
\hline $\begin{array}{l}\text { Quercus sp } \\
\text { caducifolio }\end{array}$ & 168 & 67.5 & 115 & 62.2 & 71 & 80.7 & 44 & 91.6 \\
\hline Fabaceae & 26 & 10.4 & & & 2 & 2.3 & 1 & 2.1 \\
\hline Alnus sp. & 16 & 6.4 & 35 & 19 & 1 & 1.1 & & \\
\hline Alnus/Corylus, & & & & & 5 & 5.7 & & \\
\hline Maloideae & 4 & 1.6 & & & & & & \\
\hline Betula sp. & & & 1 & 0.5 & & & & \\
\hline \multicolumn{9}{|l|}{ Fraxinus $s p$} \\
\hline Salix/Populus & 5 & 2 & 1 & 0.5 & 1 & 1.1 & & \\
\hline Corylus avellana & 22 & 8.9 & 29 & 15.8 & 3 & 3.4 & & \\
\hline Ilex aquifolium & 4 & 1.6 & & & & & & \\
\hline Frangula alnus & 1 & 0.4 & 2 & 1 & & & & \\
\hline Hedera helix & 1 & 0.4 & & & & & & \\
\hline Juglans regia & & & 2 & 1 & & & & \\
\hline Indeterminable & 2 & 0.8 & & & 5 & 5.7 & 3 & 6.3 \\
\hline TOTAL & 249 & 100 & 185 & 100 & 88 & 100 & 48 & 100 \\
\hline
\end{tabular}

\subsection{Aspectos dendrolóxicos}

Observáronse determinados aspectos dendrolóxicos, como a medición do diámetro de pólas, a frecuencia da presenza de vitrificación dos tecidos, grietas na estructura anatómica, acción de insectos xilófagos, e incluso a existencia de cicatrices nalgún dos fragmentos de carbón. Realizáronse en total 124 medicións de radios, un $10.6 \%$ do total analizado, na maior parte dos casos correspóndense con pequenas pólas de diferentes especies: Quercus sp caducifolio, Fabaceae, Corylus avellana, Alnus sp, Maloideae, Juglans regia e Salix/Populus.

A maior cantidade de medicións foron realizadas sobre pequenas pólas de entre $1 \mathrm{~mm}$ e $10 \mathrm{~mm}$. Os diámetros de maior envergadura correspóndense con fragmentos de Quercus sp caducifolio. $\mathrm{O}$ maior número de medicións realizouse sobre Corylus avellana, nos que foi posible determinar o diámetro dun $56.09 \%$ dos fragmentos identificados desta especie, que se corresponden en xeral con pequenas pólas de entre $6 \mathrm{~mm}$ e $15 \mathrm{~mm}$ (Fig. 3).

Nos carbóns estudados observáronse cicatrices en fragmentos carbonizados de madeira de carballo, en tódolos casos observados a cicatriz se localiza no leño xove, no momento de crecemento da árbore que se produce durante a primaveira. Os tecidos das árbores e arbustos poden presentar estas cicatrices por diversos motivos como feridas que afectan ó cambium, enfermidades de diverso tipo, a acción do lume, as xeadas, etc.

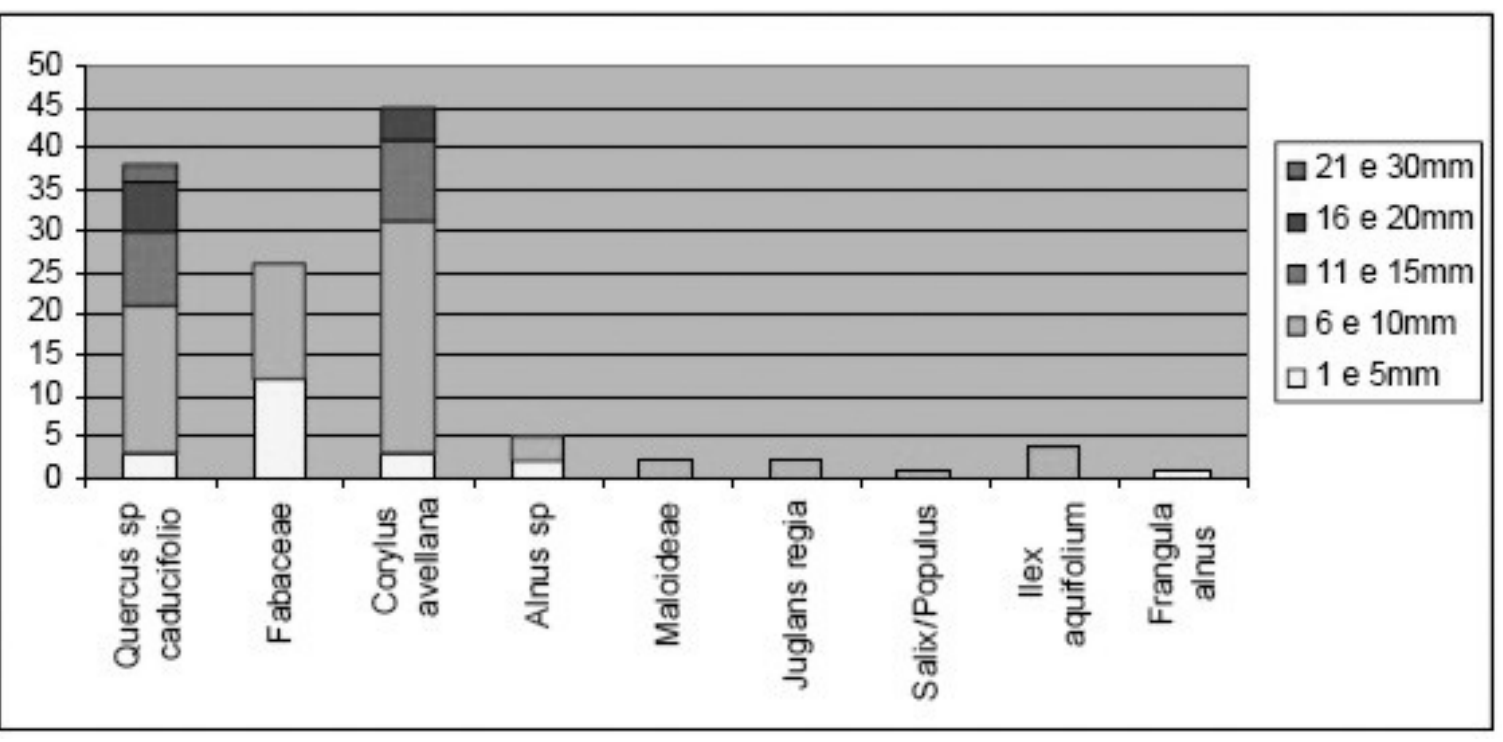

Fig. 3 - Medicións dos diámetros en relación co taxón arbóreo ou arbustivo.

Fig. 3 - Measurement of diameters in relation to the tree and shrub taxon. 
A presenza de marcas de xilófagos é anecdótica unicamente se apreciou nun $0.65 \%$ das mostras analizadas. As especies afectadas pola acción destos insectos son Corylus avellana (UE275, UE060, UE054), Fraxinus sp (UE148), Alnus sp (UE400), Fabaceae (UE060).

Algúns dos fragmentos que presentan este tipo de alteración presentan marcas de traballo. Os insectos xilófagos atacan unicamente á madeira morta polo que a constatación da existencia da súa acción sobre a madeira pode indicar ben o consumo de madeira morta producida de maneira natural polas árbores ou madeira viva contaminada no pé da árbore ou a recolección de madeira verde que é almacenada. No caso de obxectos elaborados en madeira ou utilizados como elementos constructivos adoitan presentar en moitas ocasións este tipo de marcas (CARRIÓN \& BADAL, 2004; MARGUERIE \& HUNOT, 2007).

A presenza de grietas radiais é moi común nos carbóns, e depende habitualmente da estructura anatómica específica das diferentes especies (son máis frecuentes no caso de taxóns con radios multiseriados como Quercus sp caducifolio), a localización na parte do tronco ou da póla (son menos habituais cerca do cerne), o nivel de humidade e da temperatura acadada durante a combustión. A presenza de tecidos vitrificados é consecuencia da fusión dos diferentes compoñentes anatómicos da madeira, cando o proceso de vitrificación chega ó seu estadio final non permite unha identificación anatómica. Observouse a presenza de vitrificación dos tecidos nun $8.1 \%$ dos casos, unha porcentaxe pouco significativa. Os taxóns que presentan vitrificación son Juglans regia, Fabaceae e Quercus sp caducifolio, o que podería indicar a combustión destas especies cando contiñan aínda un elevado grao de humidade.

A vitrificación soe ir asociada coa presenza de grietas radiais. Normalmente este tipo de alteración afecta máis a pequenas pólas. As causas da vitrificación non se coñecen exactamente, e pode producirse por varios motivos: a combustión rápida a altas temperaturas, ou incluso condicións específicas de combustión e tafonómicas, como a queima de madeira verde en condicións anaeróbicas (MARGUERIE \& HUNOT, 2007).

\subsection{Xestión do combustible}

O conxunto de carbóns estudados na análise antracolóxica permite obter datos sobre as estratexias de aprovisionamento e uso dos recursos forestais durante $\mathrm{o}$ periodo de ocupación do asentamento, dende inicios do s. II ANE ata finais do do s. I da nosa era.
O estudo da ubicuidade dos diferentes taxóns nas diferentes estructuras, é dicir a aparición recurrente dun taxón, indica un uso preferente dunha determinada especie (Táboa 4).

A análise da recurrencia de aparición das diferentes especies en relación ás unidades estratigráficas de procedencia minimiza a sobrerrepresentación de determinados taxóns en base ó reconto do número de fragmentos (PIQUÉ, 1999).

Taboa 4 - Número de fragmentos e ubicuidade nas unidades estratigráficas dos taxóns determinados.

Table 4 - Number of fragments and ubiquity in certain taxa of stratigraphic unit.

\begin{tabular}{|l|c|c|c|c|}
\hline TAXóN & $\begin{array}{c}\mathbf{N}^{\mathbf{0}} \\
\text { Frags. }\end{array}$ & $\mathbf{\%}$ & $\begin{array}{c}\text { Ubicui- } \\
\text { dade } \\
\text { (UEs) }\end{array}$ & $\mathbf{\%}$ \\
\hline $\begin{array}{l}\text { Quercus sp } \\
\text { caducifolio }\end{array}$ & 818 & 71.3 & 38 & 92.68 \\
\hline Fabaceae & 116 & 10.1 & 25 & 60.97 \\
\hline $\begin{array}{l}\text { Corylus } \\
\text { avellana }\end{array}$ & 82 & 7.1 & 14 & 34.1 \\
\hline Alnus sp & 80 & 6.9 & 12 & 29.26 \\
\hline Frangula alnus & 12 & 1.04 & 5 & 12.1 \\
\hline Maloideae & 15 & 1.3 & 6 & 14.6 \\
\hline Salix/Populus & 9 & 0.78 & 5 & 12.1 \\
\hline Juglans regia & 5 & 0.4 & 2 & 4.8 \\
\hline Ilex aguifolium & 4 & 0.3 & 1 & 2.4 \\
\hline Fraxinus sp & 2 & 0.1 & 2 & 4.8 \\
\hline Alnus/Corylus & 1 & 0.08 & 1 & 2.4 \\
\hline Betula sp & 1 & 0.08 & 1 & 2.4 \\
\hline Hedera helix & 1 & 0.08 & 1 & 2.4 \\
\hline TOTAL & $\mathbf{1 1 4 6}$ & & $\mathbf{4 1}$ & \\
\hline
\end{tabular}

En Castrolandín a especie que aparece representada máis recurrentemente é Quercus sp caducifolio, seguida de Fabaceae, e de especies de ribeira como Corylus avellana, Alnus sp, Maloideae, Frangula alnus e Salix/Populus. Existe unha explotación combinada do bosque de caducifolios do que se obtén a madeira de carballo, xunto coas formacións de matogueira representadas polas fabáceas, e co bosque de ribeira do que se aproveitan multitude de especies arbóreas. Hai unha clara preferencia pola utilización de especies arbóreas fronte ás arbustivas, tanto para a obtención de combustibles como para a confección de obxectos en madeira (Fig. 4).

Os ámbitos teóricos de obtención da materia prima e manufacturas a través de mecanismo de explotación ou intercambio elaborados para a o periodo castrexo (CARBALLO, 2002) sinalan a zona inmediata ó asentamento, entre $1 \mathrm{~km}$ e $2 \mathrm{~km}$ de distancia como a área na que se explotan os recursos forestais, onde se obteñen os alimentos, e materias primas como a pedra ou a arxila. Neste caso a partir da localización dos cursos de auga ós 
que se vinculan as especies de ribeira identificadas podemos sinalar parcialmente a área de captación da que se obteñen estas madeiras utilizadas posteriormente tanto como combustibles como madeira para a construcción ou a elaboración de artefactos.

No caso de Castrolandín as zonas vinculadas a cursos fluviais, ás que se asocian os bosques de ribeira, máis próximas estarían a $0.1 \mathrm{~km}$ cara o Norte, e $0.3 \mathrm{~km}$ cara o Sur, e as máis alonxadas situadas cara o Este e o Oeste estarían a $1.5 \mathrm{~km}$ e $1.2 \mathrm{~km}$ respectivamente. As especies de ribeira serían as predominantes no entorno do asentamento, de aí a importancia da súa representación, especialmente se observamos a ubicuidade dos taxóns que integran estos bosques xa que representan o $35.64 \%$, a pesar de que a formación arbórea máis explotada é o bosque mixto de caducifolios, co carballo como a madeira máis utilizada se observamos a recurrencia do seu uso nas unidades estratigráficas $(41.99 \%)$ e o número de fragmentos (76.7 \%) (Fig. 5).

Os vales e ladeiras suaves probablemente ocupados por bosques mixtos de caducifolios ou carballeiras estarían na zona Oeste do asentamento. Nas zonas marxinais deste bosque a matogueira ten un papel moi importante para a obtención dos combustibles ou incluso como forraxe para os animais ou material de construcción.

A extensión deste tipo de formacións pode ser favorecida intencionalmente polos habitantes do castro co fin de aproveitar estas prantas mediante a realización de cortas ou incendios.

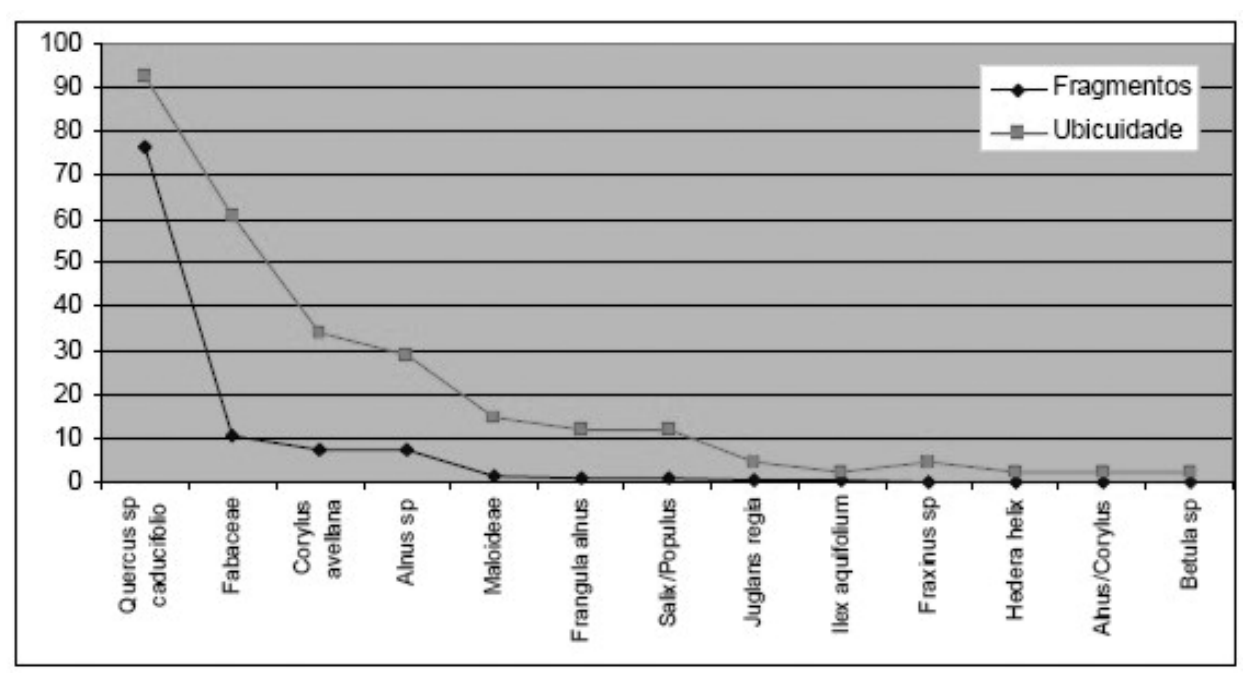

Fig. 4 - Comparación entre o número total de fragmentos e a ubicuidade dos taxóns nas diferentes unidades estratigráficas.

Fig. 4 - Comparison between the total number of fragments and ubiquity of taxa in different stratigraphic units.

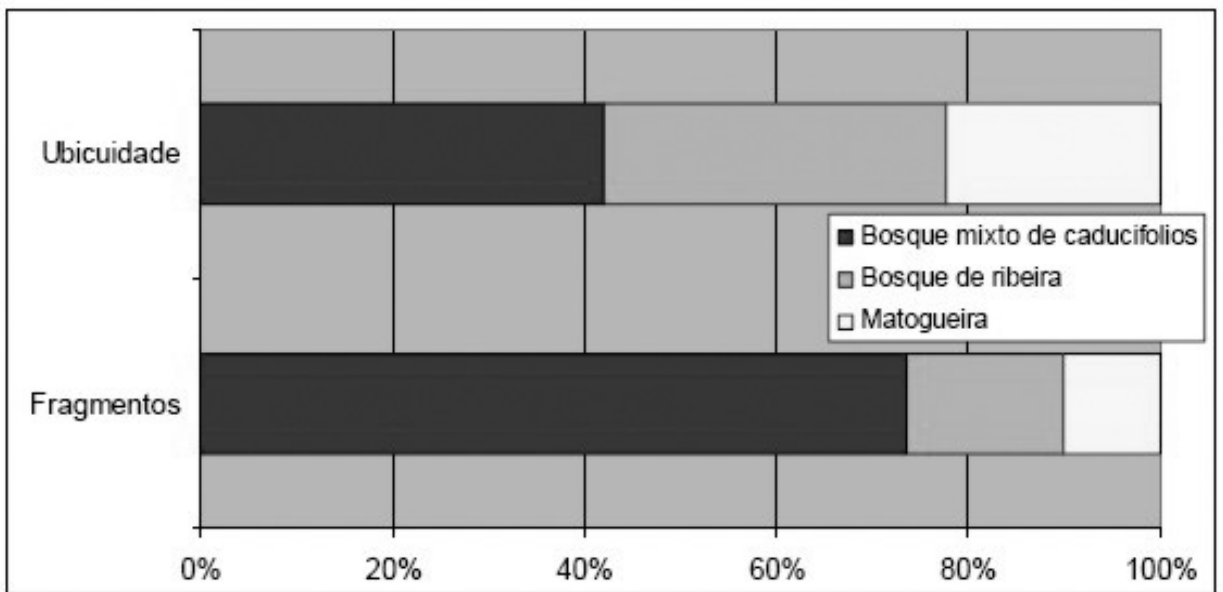

Fig. 5 - Comparación entre o número total de fragmentos e a ubicuidade das diferentes formacións identificadas.

Fig. 5 - Comparison between the total number of fragments and ubiquity of the different groups of species identified. 
As xestas e toxos, así como os bidueiros son especies pioneiras e pirófitas que medran favorecidas pola acción do lume sobre as formacións herbáceas e boscosas, ademais as primeiras favorecen a rexeneración dos solos degradados mediante a fixación do nitróxeno.

Como sinalamos anteriormente a recolección de pólas de pequeno calibre ten unha certa importancia na mostra analizada polo que podemos atoparnos ante unha recolección preferente deste tipo de leña. Este tipo de leña é facilmente transportable, ademáis de permitir unha recolección sen utilizar un instrumental específico, simplemente a man, coa axuda dun lazo, ou con pequenas ferramentas de corte como coitelos, fouces ou podóns. Ademais de que probablemente fora abundante no entorno, pola propia poda natural de determinadas especies que producen madeira morta que pode ser recollida do chan ou do pé da árbore, como podería ser o caso da abelaira, un arbusto ou pequena árbore que se ramifica dende a cepa, sen un tronco principal definido (LÓPEZ, 2002) polo que é sinxelo cortar varas duns tamaños facilmente transportables, ademáis de producir unha importante cantidade de madeira morta que está dispoñible a nivel do chan (NEWMAN et al., 2007).

Non podemos desbotar de tódolos xeitos que a selección de pequenas pólas non fora destinada á confección de elementos de cestería, entramados para delimitacións interiores ou exteriores, confección de recipientes ou mangos de ferramentas, etc e que os residuos derivados destas actividades pasaran a formar parte do rexistro antracolóxico debido a un incendio fortuito ou á eliminación mediante o lume deste tipo de residuos.

As varas longas e flexibles da abelaira ou do salgueiro utilízanse en cestería, as de carballo eran utilizadas nas seves ou peches realizados con madeira cos que se delimitaban prados e cultivos no mundo tradicional, en ocasións combinando paus de carballo e entramados de abelaira (BLANCO, 1996), as xestas (Fabaceae) son utilizadas para confeccionar os teitos de construccións debido á súa resistencia á acción de roedores e insectos (TORRES, 2003), etc.

Para poder observar a existencia de continuidades ou cambios no consumo de combustibles leñosos no asentamento, agrupamos os resultados a partir dun criterio cronolóxico utilizando as fases constructivas definidas durante a intervención realizada no 2005. A primeira fase corresponderíase coa construcción de edificacións circulares en pedra xunto con fondos de cabana realizados en materiais perecedoiros (Construccións A, E, K, I, D). Durante o segundo momento refórmanse algunhas das construccións e edifícanse outras, entre elas unha construcción circular con vestíbulo e outra de planta rectangular
(Construccións G, J, L, H, e ampliación da Construcción D). A terceira fase estaría documentada a partir da reforma realizada nunha das construccións edificadas durante a segunda fase (dependencia anexa á Construcción $\mathrm{H}$, desta última fase non temos datos antracolóxicos). O resto de datos vinculados a construccións que non son adscribibles a ningunha das fases foron agrupados como indeterminados (Construccións $\mathrm{B}, \mathrm{C}, \mathrm{F}$, espacios entre as Construccións D e F, B e C, E exterior da Construcción B) (Táboa 5).

Táboa 5 - Distribución de taxóns en relación coas fases constructivas.

Table 5 - Distribution of taxa in relation to the constructive phase.

\begin{tabular}{|l|r|r|r|r|r|r|}
\hline \multirow{2}{*}{ TAXóN } & \multicolumn{2}{|l|}{ Fase I } & \multicolumn{2}{l|}{ Fase II } & \multicolumn{2}{l|}{$\begin{array}{l}\text { Sen } \\
\text { determinar }\end{array}$} \\
\cline { 2 - 7 } & $\mathbf{N}^{\mathbf{0}}$ & $\mathbf{\%}$ & $\mathbf{N}^{\mathbf{0}}$ & $\mathbf{\%}$ & $\mathbf{N}^{\mathbf{0}}$ & $\mathbf{\%}$ \\
\hline $\begin{array}{l}\text { Quercus sp. } \\
\text { caducifolio }\end{array}$ & 183 & 76.9 & 52 & 66 & 494 & 69.3 \\
\hline Fabaceae & 41 & 17.2 & 10 & 13 & 51 & 7.2 \\
\hline $\begin{array}{l}\text { Corylus } \\
\text { avellana }\end{array}$ & 5 & 2.1 & 6 & 7.6 & 60 & 8.4 \\
\hline Alnus sp & 1 & 0.4 & 11 & 14 & 60 & 8.4 \\
\hline $\begin{array}{l}\text { Erangula } \\
\text { alnus }\end{array}$ & 1 & 0.4 & & & 11 & 1.6 \\
\hline Maloideae & 1 & 0.4 & & & 9 & 1.3 \\
\hline Alnus/Corylus & & & & & 0 & 0 \\
\hline Salix/Populus & & & & & 8 & 1.1 \\
\hline Juglans regia & & & & & 5 & 0.8 \\
\hline Ilex aquifolium & & & & & 4 & 0.6 \\
\hline Betula sp & & & & & 1 & 0.1 \\
\hline Eraxinus sp & & & & & 1 & 0.14 \\
\hline Hedera helix & & & & & 1 & 0.1 \\
\hline Indeterminable & 6 & 2.6 & & & 8 & 1 \\
\hline TOTAL & $\mathbf{2 3 8}$ & $\mathbf{1 0 0}$ & $\mathbf{7 9}$ & $\mathbf{1 0 0}$ & $\mathbf{7 1 3}$ & $\mathbf{1 0 0}$ \\
\hline
\end{tabular}

A partir dos datos obtidos podemos observar unha certa continuidade no patrón de explotación de combustibles, co carballo e as fabáceas como as especies fundamentais das que se obteñen os combustibles leñosos utilizados, seguidos das especies de ribeira. Na segunda fase hai unha maior importancia Alnus e Corylus, sen embargo sería necesario ampliar a mostra para confirmar un cambio na extratexia de explotación.

\subsection{Manufacturas en madeira}

A excepcional conservación de obxectos de madeira carbonizada con sinais de traballo no xacemento de Castrolandín permítenos diferenciar as prácticas forestais destinadas á obtención de combustibles leñosos daquelas relacionadas co traballo da madeira para a elaboración de artefactos ou elementos de constructivos. As cualidades da madeira a traballar difiren daquelas apreciadas nas 
que se utilizan como combustibles, neste caso obsérvanse características da madeira como a dureza ou a lixereza, a porosidade, a tenacidade, a flexibilidade, a cor, o olor, a presenza de resinas ou gomas, a presenza de vetas ou nudos. Estas características da madeira son tomadas en conta no momento de seleccionar a mellor especie para conseguir unha determinada forma ou para un uso específico. As madeiras brandas teñen unha fibra de trama ancha e son traballadas fácilmente con ferramentas de corte, mentres que si é torneada rompe e astíllase, pola contra as madeiras duras cunha madeira compacta, son máis pesadas, trabállanse con dificultade con ferramentas de corte e son máis apropiadas para tornear.

En xeral podemos sinalar catro tipos de restos de madeira carbonizada nos que se identificaron marcas de traballo:

- restos de tala e obxectos inacabados, pequenas pólas nas que se aprecian os planos de corte;

- restos de traballo de carpintería como achas de madeira, pequenos fragmentos en forma de cuña, etc.;

- obxectos con evidencias de traballo de carpintería como poden ser os rebaixes, os cortes para formatizar as pezas, etc.;

- fragmentos de contedores de madeira con acabados coidados conseguidos mediante $\mathrm{o}$ puído, etc.

Para abordar a análise deste tipo de restos arqueobotánicos, nos que se poden apreciar evidencias de tala e corte, extracción de materia, acabados das superficies como o puído, etc, observáronse os fragmentos na lupa binocular para ver as características das superficies das diferentes pezas, comparándose coas descricións realizadas na bibliografía especializada e realizáronse reproduccións experimentais de diferentes xestos técnicos.

A partir da determinación de restos de carpintería podemos reconstruir algúns dos xestos técnicos empregados durante o traballo da madeira no xacemento de Castrolandín. Obsérvase como na madeira de Quercus sp caducifolio da que se explotan dende pequenas pólas ata troncos, para obter segmentos ou fragmentos das mesmas realízanse cortes radiais dende o cerne ata $o$ exterior. Identificáronse tamén pequenos fragmentos en forma de cuña probablemente resultado da utilización da machada ou da aixola para a extracción de materia e a formatización de determinadas pezas. Unha vez obtido o fragmento da forma desexada ben a partir dun tronco ou dunha póla, éste segméntase utilizando diversos obxectos cortantes, que deixan planos de corte especialmente visibles en especies de madeira dura e densa como pode ser o acivro (Fig. 6). Tamén documentamos a utilización de gubias para a extracción de madeira e a realización de pequenos rebaixes nestos fragmentos.

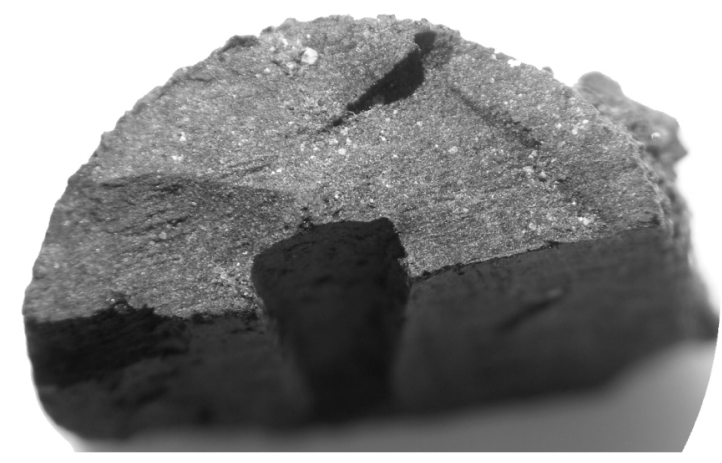

Fig. 6 - Segmento con sinais de traballo dunha pequena póla de acivro.

Fig. 6 - Little branch segment of holly tree with signs of working.

En xeral os obxectos identificados en Castrolandín corresponderíanse con recipientes, mangos de ferramentas, elementos constructivos, etc. As manufacturas en madeira eran probablemente moi habituais nos asentamentos castrexos, actualmente están documentadas en xacementos como Castromao (Celanova, Ourense), Castrovite (A Estrada, Pontevedra), Cameixa (Boborás, Ourense), Montealegre (Moaña, Pontevedra) ou mediante mineralización no caso do Castro Grande de O Neixón (Boiro, A Coruña). Existe unha selección de diferentes especies para a elaboración de manufacturas en madeira, en cada caso adecuadas ó uso final das pezas. A lista de taxóns cos que se elaboran obxectos neste xacemento é moito máis limitada daqueles utilizados como combustibles: ameneiro (Alnus sp), carballo (Quercus sp caducifolio), freixo (Fraxinus $\mathrm{sp}$ ), abelaira (Corylus avellana) e acivro (Ilex aquifolium) (Táboa 6).

Táboa 6 - Usos determinados en Castrolandín das diferentes especies con marcas de traballo.

Table 6 - Use of differents species with different traces of work.

\begin{tabular}{|c|c|c|}
\hline UsO & ESPECIE & $\begin{array}{c}\mathbf{N}^{0} . \\
\text { FraGS. }\end{array}$ \\
\hline Recipientes & Alnus sp & 5 \\
\hline \multirow{3}{*}{$\begin{array}{l}\text { Materiais de } \\
\text { construcción: } \\
\text { táboas } \\
\text { cuñas } \\
\text { encaixes }\end{array}$} & Quercus sp caducifolio & 3 \\
\hline & Fraxinus sp & 1 \\
\hline & $\begin{array}{l}\text { Quercus sp caducifolio } \\
+ \\
\text { Corylus avellana }\end{array}$ & 1 \\
\hline $\begin{array}{l}\text { Ferramenta: } \\
\text { mango de madeira }\end{array}$ & Quercus sp caducifolio & 1 \\
\hline Indeterminado & Ilex aquifolium & 4 \\
\hline
\end{tabular}


Como recipientes identificáronse aqueles fragmentos con borde ou con marcas de puído no seu interior, todos se corresponden con ameneiro (Alnus sp), unha árbore que proporciona unha madeira cunha tonalidade moi clara no momento de ser cortada pero que despois toma unha tonalidade avermellada ou anaranxada (LÓPEZ, 2002), a súa madeira é lixeira, de grao fino e branda. As súas características fan que sexa facilmente traballable con instrumentos de corte, ademais toma ben o pulimento.

Os materiais de construccións estaban elaborados en carballo, freixo e abelaira.

A madeira de carballo (Quercus sp caducifolio) é dura e de gran solidez, de cor pardo-leonado, ten o grao fino e os aneis de crecemento ben marcados, moi resistente á putrefacción incluso dentro da auga e adecuada para pulimentar (LÓPEZ 2002 \& ABELLA, 2003). A súa utilización como elemento estructural para confeccionar vigas e postes, encaixes de pezas de madeira, é debida á súa resistencia á compresión e flexión utilízase para mangos de ferramentas, etc.

A madeira de freixo (Fraxinus sp) é branca, dura e tenaz, de fibras longas e compactación media (LÓPEZ, 2002; ABELLA, 2003). Moi adecuada cando se require elasticidade e flexibilidade, aínda que unha vez seca é excepcionalmente ríxida, ademais de ser moi resistente ó choque e ás vibracións polo que é utilizada para a confección de todo tipo de obxectos aínda que é perecedeira e incadecuada para permanecer á intemperie.

Un dos obxectos identificados é unha póla de carballo seccionada á metade, na zona cortada e adheridas á mesma determináronse varias pequenas varas de abelaira.

A madeira de abelaira (Corylus avellana) é semidura, correosa e flexible, moi tenaz e pouco duradeira (LÓPEZ, 2002; ABELLA, 2003). As varas da abelaira longas e flexibles utilízanse para confeccionar entramados, ou obxectos de cestería, ademáis de confeccionar bastóns.

$\mathrm{O}$ acivro ten unha presenza moi puntual no rexistro antracolóxico de Castrolandín, sen embargo é significativo que todos os fragmentos determinados presentaban marcas de traballo. A madeira de acivro (Ilex aquifolium) é moi pesada, de cor branca ou grisácea, de textura fina e uniforme, carece de debuxo é dura e difícil de traballar (LÓPEZ, 2002; ABELLA 2003). Ten un secado difícil e para previr a torsión córtase en pequenas pezas. Utilízase especialmente para tornería, é resistente á calor, e con ela confecciónanse os mangos da ferramenta agrícola.

\section{Contexto Paleoambiental}

Os datos polínicos obtidos de zonas próximas proporcionan información sobre a composición do bosque, e en xeral sobre os niveis de actividade humana que poden ser reconstruídos en base á interpretación das curvas polínicas dos taxóns arbóreos e os taxóns non arbóreos respectivamente.

A análise polínica realizada sobre un paleosolo inmediatamente anterior á primeira ocupación castrexa de Alto do Castro (Cuntis, Pontevedra), datada nun momento anterior ó s. V ANE denota unha importante representación de pole arbóreo, dominando Quercus, seguido de Corylus e Alnus, e cunha presenza puntual de Betula (PARCERO, 2002). No estrato arbustivo destaca Erica, fronte á escasa representación de Fabaceae.

Os indicadores de actividades pastorís e gandeiras como Poaceae e Plantago son significativos, así como a representación de Asphodelus que indica a existencia de prácticas relacionadas coa acción do lume sobre o entorno, fundamentalmente para a obtención de pastos e zonas de cultivo mediante a realización de queimas.

Os datos polínicos sinalan polo tanto a existencia dun bosque de caducifolios, co carballo como especie predominante, acompañada en ocasións polo castiñeiro, xunto con formacións de ribeira nas que destacarían as abelairas e os ameneiros. A orla arbustiva tería unha especial importancia, especialmente no diagrama de Penalba I, con plantas pioneiras que colonizan terreos degradados como son as ericas e as fabáceas (tipo xesta-toxo). Neste derradeiro caso dende o inicio do diagrama polinico obsérvase unha forte acción do home sobre o entorno a través do uso do lume como sinala a presenza de especies pirófitas como o Asphodelus e as filicales.

Os resultados obtidos durante a realización da análise antracolóxica permiten obter unha representación parcial do entorno forestal, as especies determinadas son coincidentes coas que aparecen nas secuencias polínicas da zona, aínda que completan a paisaxe que as análises polínicas presentan xa que determinados taxóns como Ilex aquifolium, Maloideae, Frangula alnus, Fraxinus sp ou Juglans regia non están representadas. Do mesmo modo que a importante presenza de Fabaceae na secuencia antracolóxica contrasta cos resultados do pole, xa que as prantas desta especie son entomófilas e adoitan estar infrarrepresentadas.

A presenza de amieiro (Alnus glutinosa) denota a existencia dun elevado nivel de humidade, o sistema radical deste tipo de árbore adoita estar inmerso na auga ou en zonas asolagadas precisando solos de certa profundidade. As súas esixencias hídricas fan que sexa unha especie difícil de atopar fora do ámbito ribereño. Adoita ser a especie 
dominante na ripisilva acompañado doutras árbores e arbustos. As formacións de ameneiros son umbrosas polo que as especies heliófilas non medran baixo estas árbores, normalmente os taxóns que aparecen asociados son as especies planocaducifolias non esclerófilas como o freixo (Fraxinus sp), o salgueiro/chopo (Salix/Populus), a abelaira (Corylus avellana) ou o sanguiño (Frangula alnus) (Táboa 7).

Táboa 7 - Formacións coas que se relacionan as especies determinadas na análise.

Table 7 - Groups that relate to certain species in the analysis.

\begin{tabular}{|c|c|}
\hline TIPO DE TAXÓNS & No. FraGS. \\
\hline \multicolumn{2}{|l|}{ Bosque mixto } \\
\hline $\begin{array}{l}\text { Quercus sp caducifolio } \\
\text { Maloideae } \\
\text { Ilex aquifolium } \\
\text { Juglans regia } \\
\text { Betula sp. }\end{array}$ & $\begin{array}{r}818 \\
15 \\
4 \\
5 \\
1\end{array}$ \\
\hline \multicolumn{2}{|l|}{ Matogueira } \\
\hline Fabaceae & 116 \\
\hline \multicolumn{2}{|l|}{ Bosque de ribeira } \\
\hline $\begin{array}{l}\text { Corylus avellana } \\
\text { Alnus/Corylus } \\
\text { Alnus sp. } \\
\text { Erangula alnus } \\
\text { Eraxinus sp } \\
\text { Salix/Populus }\end{array}$ & $\begin{array}{r}82 \\
1 \\
80 \\
12 \\
2 \\
9\end{array}$ \\
\hline
\end{tabular}

A presenza predominante do carballo na secuencia antracolóxica indica a explotación de carballeiras ou do bosque mixto de caducifolios, co carballo como especie predominante. O carballo (Quercus robur) é unha árbore robusta que ocupa terreos profundos e húmidos como os vales ou as ladeiras suaves, preferentemente en substratos ácidos (RIGUEIRO, 2003). Neste bosque existirían claros nos que medrarían especies heliófilas e colonizadoras como as maloideas tipo espiño negro/estripo (Maloideae), o bidueiro (Betula sp) ou as fabáceas tipo xesta-toxo (Fabaceae) que se extenden debido á realización de cortas ou incendios que afectan ó bosque. Este tipo de formacións arbóreas poden ser pluriespecíficas formando parte das mesmas ademais das anteriores, árbores como o sanguiño (Frangula alnus), a abeleira (Corylus avellana), e o acivro (Ilex aquifolium), e lianas como a hedra (Hedera helix).

A presenza de Juglans regia na análise antracolóxica de Castrolandín é moi puntual, sendo unha árbore que aparece asociada a carballeiras ou bosques mixtos. A súa determinación antracolóxica en xacementos da Idade do Ferro da Península Ibérica é moi esporádica (FIGUEIRAL, 1993;
Figueiral \& Bettencourt, 2004; DuQue, 2004), a pesar de sí estar representada esta especie na secuencia polínica do Noroeste dende o 8500 BP.

A partir do cambio de era Juglans e Castanea extendéndense debido á introducción de novas prácticas de silvicultura destinadas ó aproveitamento os froitos e a madeira destas especies (CONEDERA et al., 2004). A súa presenza neste xacemento pode responder ó carácter espontáneo e relicto desta especie asociada a formacións riparias desenvolvidas en solos profundos e húmidos.

\section{SÍNTESE}

Os datos sobre a explotación de especies leñosas indican o combustible durante a ocupación do asentamento castrexo de Castrolandín foi obtido do bosque mixto de caducifolios, das formacións riparias e das matogueiras de fabáceas tipo xestatoxo. O Quercus sp caducifolio é a especie utilizada preferentemente como combustible, polo número de fragmentos determinados e pola súa ubicuidade en relación con todo tipo de contextos como depósitos interiores das construccións, estructuras de combustión, e zonas exteriores exteriores. Foron identificados ademais outros usos desta especie utilizada no castro como madeira de construcción (cuñas, encaixes) ou para a elaboración de pequenos obxectos (mango).

As especies do bosque de ribeira están tamén ben representadas na secuencia, eran ademais a formación arbórea máis próxima ó asentamento, polo que as madeiras deste tipo de árbores acadan unha importante representación en conxunto, sendo Alnus sp e Corylus avellana algunhas das máis repetidamente utilizadas. A significativa representación das Fabaceae indican a explotación combinada do bosque e das formacións de matogueira, como adoita ser habitual nos asentamentos da Idade do Ferro do Noroeste da Península.

Os datos sobre o aproveitamento do entorno indican que existe unha recolección de troncos e pólas de calibre medio de Quercus sp caducifolio, en xeral troncos e pólas de calibre medio, xa que apenas se cuantifican pequenas pólas de pequeno diámetro desta especie, e pólas de pequeno calibre de Corylus avellana, Fabaceae, Juglans, Alnus, etc. As áreas de captación de leña e madeira realízase como mínimo nun radio entre $0.1 \mathrm{~km}$ e $1.5 \mathrm{~km}$ de distancia do asentamento.

A identificación de madeiras traballadas permite comezar a documentar parte do repertorio do conxunto de obxectos da vida cotiá realizados en madeira que existirían nos asentamentos deste periodo: dende os diferentes elementos 
constructivos a pequenos obxectos como mangos ou recipientes. Permite incluso apuntar a existencia dunha selección de especies coa finalidade de ser traballadas como Ilex aquifolium, da que tódolos fragmentos determinados presentaban sinais de traballo, e non foron determinadas en ningún outro lugar do asentamento polo que probablemente non fora utilizada como combustible de maneira habitual.

\section{BIBLIOGR AFIA}

ABElla, I. (2003). El hombre y la madera, Ed. Integral, Barcelona.

Blanco, E. (1996). El Caurel, las plantas y sus habitantes. Estudio etnobotánico de la Sierra del Caurel (Lugo): la importancia de las plantas para nuestros antepasados, Fundación Caixa Galicia, A Coruña.

Carballo, L.X. (2002). A Cultura Castrexa na Comarca do Deza, Colección Deza Básicos, nº 4 , Lalín.

CARRIÓN, Y. (2003). Afinidades y diferencias de las secuencias antracológicas en las vertientes mediterránea y atlántica de la Península Ibérica, Tesis doctoral, Universidad de Valencia, inédita.

CARRIÓN, Y. \& BADAL, E. (2004). La presencia de hongos e insectos xilófagos en el carbón arqueológico. Propuestas de interpretación, Avances en Arqueometría 2003, Universidad de Cádiz, pp. 98-106.

Conedera, M.; Krebs, P.; Tinner, W. \& Pradella, M. (2004). The cultivation of Castanea sativa (Mill.) in Europe, from its origin to its diffusion on a continental scale, Vegetation History and Archaeobotany, 13, pp.161179 .

Costa, M.; Morla, C. \& SÁInZ, H. (ed.) (2001). Los bosques ibéricos. Una interpretación geobotánica, Ed. Planeta, Barcelona.

DUQUE, D.M. (2004). La gestión del paisaje vegetal en la Prehistoria Reciente y Protohistoria en la Cuenca Media del Guadiana a partir de la Antracología, Universidad de Extremadura, Cáceres, inédita.

FigueIRAL, I. (1993). Charcoal analysis and the vegetational evolution of North-West Portugal, Oxford Journal of Archaeology, 12 (2), pp. 209-222.

Figueiral, I. \& Bettencourt, A.M.S. (2004). Middle/Latte Bronze Age plant communities and their exploitation in the Cávado Basin (NW Portugal) as shown by charcoal analysis: the significance and co-occurrence of Quercus (deciduous)-Fabaceae, Vegetation History and Archaeobotany, 13, pp. 219-232.
HATHER, J.G. (2000). The identification of the Northern European Woods. A guide for archaeologists and conservators, Archetype, London.

LÓPEZ, G. (2002). Guía de los árboles y arbustos de la Península Ibérica y Baleares, Ed. Mundi-Prensa, Madrid.

MARGuERIE, D. \& HunOt, J.-Y. (2007). Charcoal analysis and dendrology: data from archaeological sites in northwestern France, Journal of Archaeological Science, 34, pp. 1417-1433.

Martínez Cortizas, A.; Mi Ghall, T.; Pontevedra, X.; NóvoA, J.C.; PEITEADO, E. \& PIÑEIRO, R. (2005). Linking changes in atmospheric dust deposition, vegetation change and human activities in northwestern Spain during the last 5300 years, The Holocene, vol. 15, $\mathrm{n}^{\circ} 5$, pp. 698-706.

Newman, C.; O'Connell, M.; Dillon, M. \& Molloy, K. (2007). Interpretation of charcoal and pollen data relating to a late Iron Age ritual site in eastern Ireland: a hollistic interpretation, Vegetation History and Archaeobotany, 16, pp. 349-365.

PARCERO, C. (2002). Síntese dos traballos de escavación no xacemento castrexo de Alto do Castro, in X. Ayán. (ed.) Pasado e futuro de Castrolandín (Cuntis): unha proposta de recuperación e revalorización, Tapa, 29, pp. 59-71.

PIQUÉ, R. (1999). Quantification in Archaeobotany: Charcoal Analysis and Fire-Wood Management, in J.A. Barceló, I. Briz, \& A. Vila (eds.) New techniques for Old Times, BAR International Series 757, pp. 189-200.

PIQUÉ, R. \& Ros, M.T. (2002). La gestió dels recursos llenyosos entre els segles VI-II AC, in E. Pons (ed.) Mas Castellar de Pontós (Alt Empordà) un complex arqueolòic d'època ibèrica (Excavacions 1990-1998), Museu d'Arqueologia de Catalunya, Girona, pp. 427-439.

RigueIRO, A. (2003). Bosques e masas arboradas, in J.J. Casares (ed.) Reflexións sobre o medioambiente en Galicia, Consellería de Medio Ambiente, Xunta de Galicia, Santiago, pp. 323-357.

SCHWEINGRUBER, F.H. (1978). Mikroskopische Holzanatomie, Zurcher a.g. Zug.

SCHWEINGRUBER, F.H. (1990). Anatomie Europäischer Hölzer, Bern und Stuttgart.

TORREs J.F. (2003). La economía de los celtas de la Hispania atlántica I. Agricultura, ganadería y recursos naturales, Ed. Toxosoutos, A Coruña.

Vernet, J.L.; OGereau, P.; Figueiral, I.; MAChado, C. \& UZQUIANO, P. (2001). Guide d'identification des charbons de bois préhistoriques et récents. Sud-Ouest de l'Europe: France, Peninsule Ibérique et îles Canaries, CNRS Editions, Paris. 